We thank Dr R E Oakey, Department of Chemical Pathology, Leeds for his assistance in performing the assays on the second family.

Dr L J H Arthur died in December 1983.

\footnotetext{
References

1 France JT, Liggins GC. Placental sulphatase deficiency. Journal of Clinical Endocrinology 1969;29:138-41.

2 Taylor NF. Review: placental sulphatase deficiency. Journal of Inherited Metabolic Disease 1982;5:164-76.

3 Jobsis AC, Van Duuren CY, De Vries GP, et al. Trophoblast sulphatase deficiency associated with $\mathrm{X}$-chromosomal ichthyosis. Ned Tijdschr Geneeskd 1976;120:1980.
}

4 Crawford MD'A. Review: genetics of steroid sulphatase deficiency and X-linked ichthyosis. Journal of Inherited Metabolic Disease 1982:5:153-63.

5 Williams ML, Elias PM. Stratum corneum lipids in disorders of cornification. Increased cholesterol sulphate content of stratum corneum in recessive $\mathrm{X}$-lined ichthyosis. $J$ Clin Invest 1981;68:1404-10.

6 Shapiro LJ, Cousins L, Fluharty AL, Stevens RL, Kihara H. Steroid sulphatase deficiency. Pediatr Res 1977;11:894-7.

Correspondence to Dr A A Attenburrow, Green Wood Children's Centre, Nottingham City Hospital, Hucknall Road, Nottingham.

Received 13 June 1984

\title{
Birthweights of infants born before 30 weeks' gestation
}

\section{O G BROOKE AND N McINTOSH}

\author{
Neonatal Unit, St George's Hospital, London
}

SUMMARY We give birthweight data with centiles on 222 singleton infants born between 24 and 30 weeks' gestation at St George's Hospital, London.

Few data are available on the weights of liveborn infants of less than 30 weeks' gestation. It is, therefore, difficult to assess whether these very immature infants are unexpectedly large or small. We provide some data which may be of use to paediatricians caring for these infants.

\section{Patients and methods}

We present data on the birthweights of all singleton liveborn infants of 30 weeks' gestation or less born at this hospital and admitted to the Neonatal Unit between February 1980 and February 1984. All infants were weighed naked and without attachments on a Marsden spring balance (Marsden Weighing Machines, London). Measurements were made to an accuracy of plus or minus $5 \mathrm{~g}$. Gestation was assessed by maternal dates and antenatal ultrasound when available.

\section{Results and comment}

The Table gives the birthweight (mean (SD)) for each week of gestation between 24 and 30 weeks. There were small sex differences which did not reach statistical significance, so we have combined the data for both sexes. The Figure is a centile chart covering the same period, again with both sexes
Table Birthweights of liveborn infants between 24 and 30 weeks' gestation (both sexes combined)

\begin{tabular}{lrrrrrrr}
\hline \multicolumn{7}{c}{ Gestation (weeks) } \\
\cline { 2 - 8 } & 24 & 25 & 26 & 27 & 28 & 29 & 30 \\
\hline Number & 17 & 12 & 37 & 32 & 44 & 33 & 47 \\
Mean birthweight (g) & 634 & 845 & 891 & 1008 & 1062 & 1212 & 1394 \\
Standard deviation & 81 & 98 & 151 & 167 & 186 & 239 & 327
\end{tabular}

combined. We were unable to show the bimodal distribution of birthweight or the widening of the 75th and 90th centiles found by Milner and Richards ${ }^{1}$ in infants of less than 33 weeks' gestation. The conclusion drawn by these authors was that the higher weight peak of the bimodal distribution curve was largely formed by pregnancies of inaccurately timed gestation. It seems likely that this was so, since the absence of this phenomenon in our sample may be explained by improvements in the ultrasound assessment of pregnancies of uncertain length in the intervening 10 years. Another piece of supporting evidence is the difference in mean birthweight at 28 weeks' gestation between our sample and Milner's-his unselected infants being about $260 \mathrm{~g}$ heavier at that apparent gestation. It is unlikely that demographic differences would account for such a large effect, and we prefer to ascribe it to a reduction in the number of wrongly dated and more mature infants. Our mean birthweight and its standard deviation at 28 weeks' gestation was, however, similar to Babson's results from Oregon. ${ }^{2}$ 


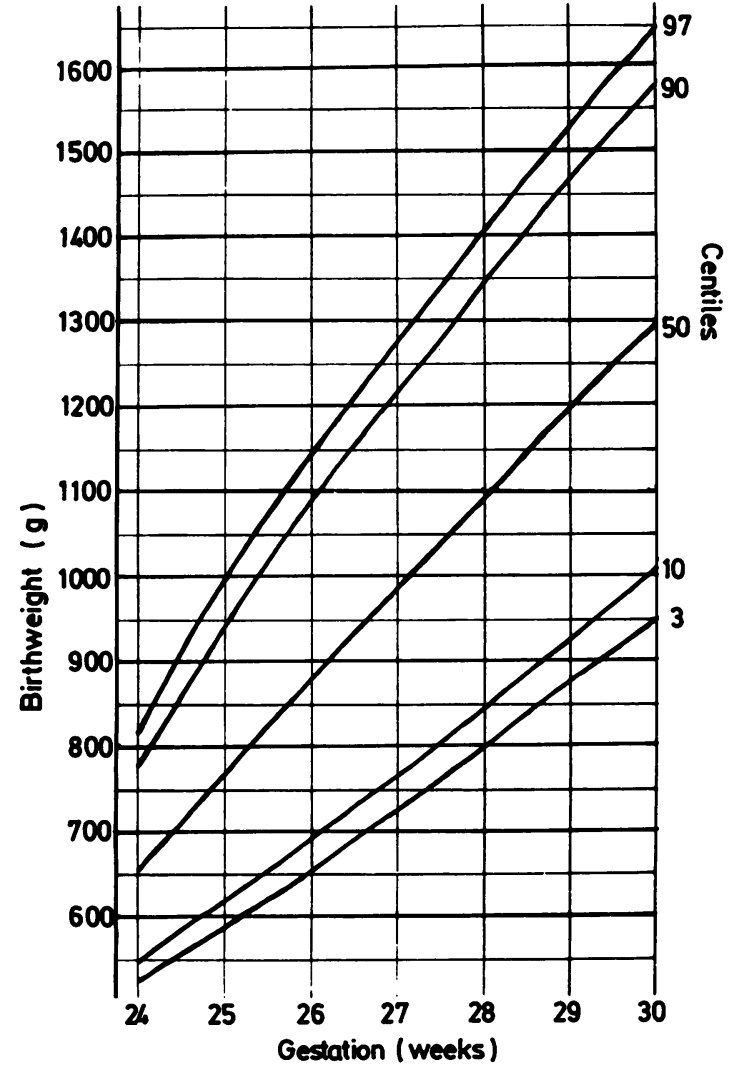

Figure Birthweight centiles of liveborn infants between 24 and 30 weeks' gestation (both sexes combined). (See Table for numbers).

It seems inevitable that there will be uncertainties in the interpretation of data such as these, which are at present very difficult to obtain for an unselected population. Our data certainly cannot be considered unselected, since many mothers were transferred antenatally for delivery at this hospital and thus represent an abnormal obstetric population. Nevertheless, since it is difficult to accumulate data on large numbers of immature infants who have been properly weighed and accurately documented, and since these infants are representative of the type usually managed in neonatal intensive care units, we feel that these figures may be of value to neonatal paediatricians.

\section{References}

1 Milner RDG, Richards B. An analysis of birth weight by gestational age of infants born in England and Wales, 1967 to 1971. Journal of Obstetrics and Gynaecology of the British Commonwealth 1974;81:956-67.

2 Babson SG. Growth of low-birth-weight infants. J Pediat 1970;77:11-8.

Correspondence to Dr O G Brooke, Neonatal Unit, St George Hospital, London SW17.

Received 4 July 1984 